\title{
Almanac 2014: congenital heart disease
}

\author{
Peter C Kahr, Gerhard-Paul Diller
}

Division of Adult Congenital and Valvular Heart Disease, Department of Cardiovascular Medicine, University Hospital Muenster, Muenster, Germany

\section{Correspondence to} Dr Peter C Kahr,

Division of Adult Congenital and Valvular Heart Disease, Department of Cardiovascular Medicine, University Hospital Münster, Albert-SchweitzerCampus 1, Gebäude: A1, Münster 48149, Germany; pckahr@gmail.com

Accepted 20 October 2014

\section{ABSTRACT}

This Almanac summarises important congenital heart disease articles published between 2012 and 2014 in Heart and other major cardiac journals. It highlights what the authors perceive to be highly relevant articles in the field. While the aim was to provide a

comprehensive overview of the area, a focus on certain areas of interest was required. The selection is, therefore, by necessity a subjective one.

\section{EPIDEMIOLOGY AND FOETAL CARDIOLOGY}

The prevalence of congenital heart disease (CHD) at birth is estimated to be between 75 and 90 per 10000 for live births and total pregnancies with subgroup analyses showing rates of termination of pregnancy up to $76 \%$ for foetuses with complex anatomy or univentricular hearts (table 1). ${ }^{1}$ A UK study also highlighted the significant variation in prenatal detection rates of CHD based on National Institute for Cardiovascular Outcome Research data and provided recommendations for how to improve screening performance and audit maternity data. ${ }^{2}{ }^{3}$ Additional research is required to delineate prognosis and comorbidities, especially for relatively infrequent prenatal findings such as isolated right aortic arch, in order to improve parent counselling. ${ }^{4}$ The prevalence of CHD in adults is now estimated to be between 3 and 6.1 per 1000 based on data from the Quebec CHD database and on a systematic review of the literature, respectively. ${ }^{5}{ }^{6}$ However, this is a dynamic population and an increase in the number of adult patients with CHD, with single ventricle physiology for example, by around $60 \%$ is predicted over the next decade. This is likely to require increased investment in human and physical capital so that patients with CHD reach their full life potential. ${ }^{78}$

\section{The single ventricle}

Currently, there are several approaches for palliation of patients with hypoplastic left heart syndrome and related RV anomalies. Surgical procedures include the 'Hybrid approach', Norwood and the Sano procedure, all of which serve to ultimately transition the patient to a complete Fontan anatomy. ${ }^{9}$ While it has been reported that the choice of palliation strategy may not affect mortality in this patient group, ${ }^{10-13}$ the optimal approach remains elusive with differences seen in specific subgroups. As an example, comparison of early and mid-term results of the 'hybrid approach' demonstrated no mortality difference despite significantly higher surgical (Aristotle) risk scores in the 'hybrid group' (see figure 1). ${ }^{14}$

Advanced imaging modalities may eventually pave the way to optimising surgical strategies and improving long-term outcomes in these challenging patients. Cardiac MRI allows visualisation of the flow dynamics in patients with a total cavopulmonary connection. ${ }^{15}$ Power loss in the Fontan tunnel - which has been suspected to be the major determinant of reduced exercise capacity in Fontanwas significantly lower in patients with an intra-atrial lateral tunnel compared with extracardiac tunnels. Although power loss increased exponentially with increasing cardiac index during dobutamine stress testing, no correlation between power loss and exercise capacity on cardiopulmonary exercise testing was demonstrated.

Although the overall mortality after the Fontan operation has decreased substantially over the last decades, ${ }^{16}{ }^{17}$ postoperative effusions, protein-losing enteropathy (PLE) and liver dysfunction remain significant challenges. In a retrospective study of 42 patients with PLE, current mortality was lower than in historic reports. ${ }^{18}$ Nevertheless, PLE remains difficult to treat and atrial arrhythmias occur in $67 \%$ of patients. This article may be of particular relevance to the clinician as it provides a detailed treatment plan for patients with PLE after the Fontan operation. Liver and renal dysfunction-common late complications of Fontan patients-may help to predict adverse late outcomes in Fontan patients. ${ }^{19}$ Consistent with expectations, increased Model for Endstage Live Disease - eXcluding INR (MELD-XI) scores-a tool to estimate renal and hepatic function - correlate with an increased risk of cardiac death or transplantation. ${ }^{20}$ Implementation of the MELD-XI score into clinical practice may be useful in predicting mid-term and long-term outcomes in this growing patient population.

Patients after the Fontan operation also have reduced skeletal muscle mass, associated with markedly impaired peak exercise capacity. ${ }^{21}$ Based on the finding of significantly decreased postexercise phosphocreatine resynthesis, the authors hypothesise the existence of a 'Fontan myopathy', which needs to be investigated in further detail. This finding is of particular relevance as the contribution of a competent muscle pump is essential to augment stroke volume and cardiac index during exercise in Fontan patients. ${ }^{22}$

\section{Surgery}

Supravalvular pulmonary stenosis (SVPS) is a major problem after the arterial switch operation for transposition of the great arteries (TGAs), with a prevalence as high as 55\% in historic studies. Recently, mid-term results from 120 patients undergoing a modified version of the arterial switch operation-with a higher transection of the neopulmonic root and excision of the coronary ostia as limited ' $\mathrm{O}$ '-shaped buttons-show a lower rate of SVPS beyond 5 years of follow-up. Freedom from reoperation for SVPS was $97.1 \%$ at 14.75 years. $^{23}$ 
Table 1 Total and live birth prevalence of congenital heart defects: the EPICARD

\begin{tabular}{|c|c|c|c|c|c|c|c|c|}
\hline \multirow[b]{2}{*}{ ACC-CHD categories } & \multirow[b]{2}{*}{$\mathbf{N}$} & \multirow{2}{*}{$\begin{array}{l}\text { LB } \\
\text { Per } \\
\text { cent }\end{array}$} & \multirow{2}{*}{$\begin{array}{l}\text { TOP } \\
\text { Per } \\
\text { cent }\end{array}$} & \multirow{2}{*}{$\begin{array}{l}\text { SB } \\
\text { Per } \\
\text { cent }\end{array}$} & \multicolumn{4}{|c|}{ Prevalence (per 10000 ) } \\
\hline & & & & & Total* & $95 \% \mathrm{Cl}$ & $\begin{array}{l}\text { Live } \\
\text { birthtt }\end{array}$ & $95 \% \mathrm{Cl}$ \\
\hline 1. Heterotaxy, including isomerism and mirror imagery & 37 & 21.6 & 75.7 & 2.7 & 1.2 & 0.8 to 1.6 & 0.2 & 0.1 to 0.5 \\
\hline 2. Anomalies of the venous return & 31 & 83.9 & 16.1 & 0.0 & 1.0 & 0.7 to 1.4 & 0.8 & 0.5 to 1.2 \\
\hline 3. Anomalies of the atria and interatrial communications & 182 & 95.6 & 4.4 & 0.0 & 5.7 & 4.9 to 6.6 & 5.5 & 4.7 to 6.4 \\
\hline 4. Anomalies of the atrioventricular junctions and valves & 213 & 51.2 & 42.7 & 6.1 & 6.7 & 5.8 to 7.7 & 3.5 & 2.8 to 4.2 \\
\hline 5. Complex anomalies of atrioventricular connections & 13 & 53.8 & 46.2 & 0.0 & 0.4 & 0.2 to 0.7 & 0.2 & 0.1 to 0.5 \\
\hline 6. Functionally univentricular hearts & 158 & 30.4 & 62.7 & 6.9 & 5.0 & 4.2 to 5.8 & 1.5 & 1.1 to 2.0 \\
\hline 7. VSDs & 1491 & 93.6 & 5.7 & 0.7 & 47.0 & 44.6 to 49.4 & 44.4 & 42.1 to 46.8 \\
\hline 8. Anomalies of the ventricular outflow tracts & 563 & 79.4 & 18.5 & 2.1 & 17.7 & 16.3 to 19.3 & 14.2 & 12.9 to 15.6 \\
\hline 9. Anomalies of the extrapericardial arterial trunks & 170 & 73.5 & 23.5 & 3.0 & 5.3 & 4.6 to 6.2 & 4.0 & 3.3 to 4.7 \\
\hline 10. Congenital anomalies of the coronary arteries & 9 & 100.0 & 0.0 & 0.0 & 0.3 & 0.1 to 0.5 & 0.3 & 0.1 to 0.5 \\
\hline All & 2867 & 81.9 & 16.3 & 1.8 & 90.3 & 87.0 to 93.6 & 74.8 & 71.8 to 77.8 \\
\hline All, excluding cases associated with chromosomal anomalies & 2471 & 89.2 & 9.8 & 1.0 & 77.8 & 74.8 to 80.9 & 68.4 & 67.3 to 73.2 \\
\hline All, excluding cases associated with chromosomal or other anomalies & 2036 & 92.8 & 6.4 & 0.8 & 64.1 & 61.4 to 67.0 & 60.2 & 57.5 to 62.9 \\
\hline $\begin{array}{l}\text { All, excluding cases associated with chromosomal or other anomalies and } \\
\text { IVSD }\end{array}$ & 930 & 84.2 & 14.0 & 1.8 & 29.3 & 27.4 to 31.2 & 24.9 & 23.2 to 26.7 \\
\hline
\end{tabular}

The authors attribute these outcomes to their technique that leaves the transected edge of the neopulmonic artery intact, but caution that future research is required to validate these findings.

Long-term follow-up data on $>1700$ adults after Ross procedure in the Netherlands and Germany demonstrated good durability of the pulmonary conduits with a rate of freedom from regurgitation grade $\geq 2+$ of $95 \%$ after 14 years, and freedom from reintervention of $80 \%$ at 15 years follow-up. ${ }^{24}$

New data from the randomised Safe Paediatric Euglycemia After Cardiac Surgery trial demonstrated that patients $>60$ days of age benefited from tight postoperative glycaemic control with lower rate of infections, In contrast, younger patients showed an increased incidence of postoperative infections. ${ }^{25}$ Further trials are required to investigate the exact conditions under which tight glycaemic control may be advisable.

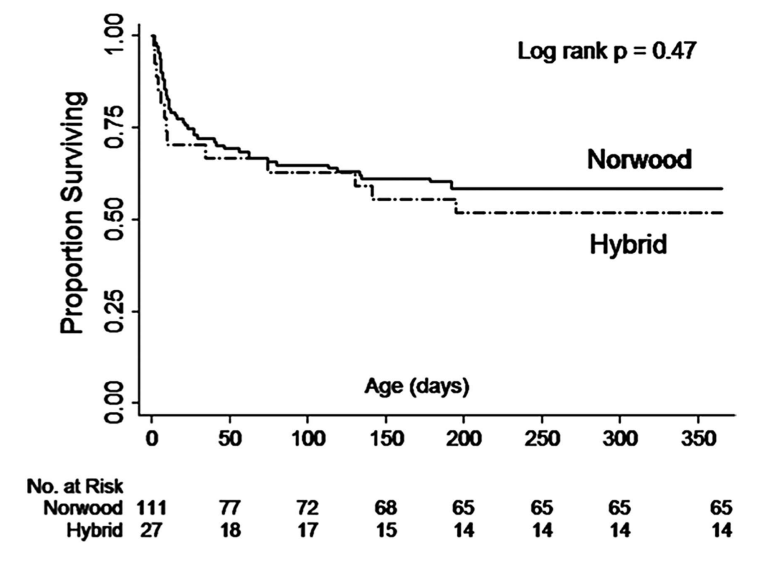

Figure 1 Interstage survival after the Norwood and Hybrid procedures. Retrospective analysis of survival data from the UK. Kaplan-Meier curve demonstrates no difference in survival despite significantly different Aristotle's scores between the two groups. Adapted from Lloyd et al. ${ }^{14}$
Two subjects of continuing discussion between surgeons and interventionalists are congenital aortic stenosis and ventricular septal defects. ${ }^{26}$ Recently, mid-term follow-up at a mean duration of $10 \pm 7$ years after primary aortic stenosis treatment during the 1 st year of life showed increased rate of reintervention in patients with balloon valvuloplasty (HR 4.0, $\mathrm{p}=0.001) .{ }^{27}$ In a prospective randomised controlled trial, 229 children with perimembranous ventricular septal defect were assigned to surgical or interventional defect closure. In this study, interventional closure was associated with less myocardial injury (lower Creatine Kinase -MB (CK-MB) and cTnI levels), shorter hospital stays, reduced medical costs and faster recovery times. $^{28}$ The authors state that interventional closure appears to be the method of choice. However, at 2 years of follow-up there was no difference in closure rate, adverse events, and complications between groups and the issue of late atrioventricular block remains to be addressed.

Innovatively, postoperative support of families with videoconferencing has been demonstrated to be feasible and to reduce rehospitalisations of infants with CHD. ${ }^{29}$ Computerised techniques have also been shown to help surgeons monitor their risk-adjusted inhospital outcomes and compare it to overregional benchmarks. ${ }^{30-32}$

\section{Tetralogy of Fallot}

In the last decades the operative treatment has dramatically improved with very low early mortality and morbidity. Therefore, the focus of attention is shifting to improving late outcomes of patients with Tetralogy of Fallot (ToF) from their third decade of life onwards. In a study from the UK, long-term outcome of patients with ToF was characterised with a duration of follow-up up to 45 years. $^{33}$ The authors demonstrate that the annual probability of death remains fourfold higher than that of the general population throughout the first five decades of life. In a large multinational study (International Multicentre TOF Registry; INdiCaTOR), 873 adults with ToF were screened for risk factors that are predictive of death or sustained ventricular tachycardia. ${ }^{34} 35$ Based on cardiac MRI measurements, the 
authors identified RV and LVEF, RV mass index, RV mass-to-volume ratio and history of atrial arrhythmias as novel risk factors for late adverse outcome (see figure 2). Exercise capacity and LV function appear to be maintained in adult patients with ToF with increased RV end-diastolic volume index $\left(>150 \mathrm{~mL} / \mathrm{m}^{2}\right)^{36}$ and are not useful to predicting the degree of RV dysfunction. Pulmonic valve regurgitation is one of the main causes of decreased RV function in patients with ToF, although it may be tolerated for decades in some individuals. ${ }^{37} \mathrm{~A}$ recent meta-analysis of outcomes after pulmonary valve replacement (PVR) including the data from more than 3100 patients, demonstrated that pooled 30 -day mortality was $0.87 \%$ and 5 -year mortality was $2.2 \% .{ }^{38}$ The risk for re-PVR was estimated to be $4.9 \%$ after 5 years. Although publication biases are a major limitation of these findings, PVR appears to be a safe treatment option. Given this low risk, increasing numbers of asymptomatic patients now undergo PVR, although optimal timing remains uncertain. $^{39}$

Research has also focused on delineating the role of the LV in determining long-term outcome in patients with ToF. In a sample of 413 adult patients with ToF, decreased LV function as assessed by transthoracic echocardiography correlated with a greater risk of sudden cardiac death or life-threatening ventricular arrhythmias. ${ }^{40}$ This finding was independent of QRS prolongation and appears to be an additional risk predictor for this patient population.

In a large multicentre study, echocardiographic screening of 474 adults with repaired $\mathrm{ToF}^{41}$ showed that only $6.6 \%$ of patients had an increased aortic diameter based on an observed-to-expected ratio $>1.5$. This relatively small proportion of patients is reassuring as previous estimates from smaller studies were much higher. Although it has previously been argued that immediate ToF repair in infancy may reduce the dilatation of the aortic root, no correlation between the duration of systemic-to-pulmonary shunt and the aortic diameter could be identified. Similarly, right aortic arch and aortic regurgitation were not predictive of increased aortic root diameter.

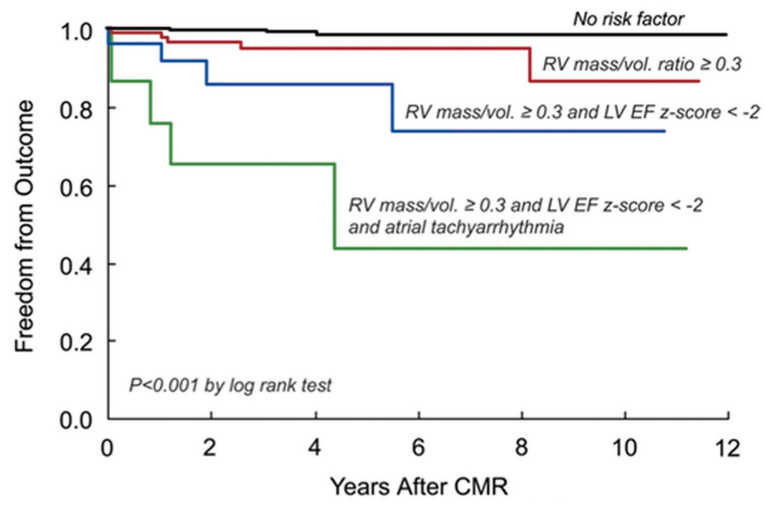

No. at Risk:

No risk factors 435

$R V$ mass $/ v o l .2 \geq 0.3$

RV mass/vol. $\geq 0.3$

+ LVEF $z<-2$

All three factors 15

249
69
16
6

113
43
11
5

$\begin{array}{rrr}22 & 2 & 1 \\ 29 & 13 & 7 \\ 7 & 6 & 3 \\ 2 & 1 & 1\end{array}$

Figure 2 Predictors of death and sustained VT in patients with repaired tetralogy of Fallot (ToF). Data from the INDICATOR cohort demonstrate that RV mass/volume ratio $\geq 0.3$, LVEF z-score $<-2$ and atrial tachyarrhythmias are most predictive of negative outcome in contemporary patients with repaired ToF. Adapted from Valente et al. ${ }^{34}$ CMR, Cardiac Magnetic Resonance Imaging; VT, Ventricular Tachycardia.

\section{Transposition of the great arteries}

Long-term follow-up data on 400 patients operated with atrial switch operation for D-Transposition of the Great Arteries (D-TGA) between 1983 and 1999 (median follow-up time 18.7 years) was recently published from a single North American centre. ${ }^{42}$ The investigators found that overall and arrhythmia-free survival at 25 years was around $97 \%$ in those patients that survived the immediate perioperative period. These results compare favourably with the much higher arrhythmia burden and incidence of sudden death previously reported in patients with atrial switch operation (Mustard, Senning). Freedom from any adverse events at 25 years was estimated to be $92.9 \%$. At latest follow-up, LV function was excellent in most cases and $97 \%$ of patients presented in NYHA class I. The few deaths reported in this publication were presumably related to myocardial infarction or presumed arrhythmic aetiology.

Despite the beneficial effects of renin-angiotensin-inhibition for patients with LV dysfunction, previous small trials in patients with a systemic RV did not demonstrate a similar effect in this patient population. The lack of benefit of renin-angiotensin inhibition for a systemic RV is now corroborated by a larger multicentre, double-blind, parallel, randomised controlled trial involving 88 adults with transposition of TGA. ${ }^{43}$ In this study, no effects of valsartan $160 \mathrm{mg}$ twice daily on RV EF or exercise capacity could be demonstrated at 3 years of follow-up.

In a prospective study, RV end-diastolic volume index $>150 \mathrm{~mL} / \mathrm{m}^{2}$ and peak systolic blood pressure below $180 \mathrm{~mm} \mathrm{Hg}$ during exercise testing were associated with adverse cardiac events based on a combined end point including death, ventricular tachycardia, transient ischaemic attack, myocardial infarction, increase in NYHA functional class or hospitalisation for worsening symptoms of heart failure (HF). ${ }^{44}$ Patients with these characteristics had a 20-fold higher annual event rate. Classical parameters from ECG and transthoracic echocardiography were found to be less predictive and, thus, MRI and exercise test were recommended to be implemented as additional components of standard follow-up in these patients.

In a study of 91 consecutive patients that underwent Mustard operation before 1980 (median follow-up 35 years), cumulative survival was $80 \%$ after 20 years, $77 \%$ after 30 years and $68 \%$ after 39 years. ${ }^{45}$ Although exercise capacity remained relatively stable during the most recent 10 years of follow-up in this cohort, RV function decreases steadily while the prevalence of arrhythmias and HF increase significantly.

\section{Pulmonary hypertension}

In a large cohort of contemporary patients with Eisenmenger syndrome, echocardiographic parameters associated with mortality included ${ }^{46}$ indices of RV function (tricuspid annular plane systolic excursion, the ratio of RV effective systolic to diastolic duration) and right atrial area. Application of a novel score combining these predictors may help to risk stratify patients with Eisenmenger syndrome, particularly when assessment of functional class is otherwise difficult. In addition, brain-natriuretic peptide (BNP) levels have been shown to be related to outcome in this population. ${ }^{47}$ Observational data from a large adult CHD centre in the UK demonstrated that 6 min walking distance and baseline oxygen-saturations were strong predictors of death in 210 adult patients with Eisenmenger syndrome, ${ }^{48}$ while traditional markers of adverse outcome like functional class or peak exercise oxygen-saturations did not correlate with death. The authors state that patients who do not reach a $6 \mathrm{~min}$ 
walk distance $\geq 350 \mathrm{~m}$ or with baseline oxygen-saturations $<85 \%$ have a threefold increased risk of mortality.

In the paediatric pulmonary arterial hypertension (PAH) population, sildenafil add-on therapy appears to be a viable option when bosentan monotherapy fails. ${ }^{49}$ Preliminary data on outcomes in paediatric patients with PAH from large multinational registries show that overall survival has significantly improved in comparison to historic samples, but there are discrepancies between the reports in reported survival rates of $\mathrm{PAH}$ related to $\mathrm{CHD}$ versus idiopathic/familial $\mathrm{PAH}^{50}{ }^{51}$ Further research will be necessary to investigate these differences with regard to survival, risk predictors and optimal treatment in further detail.

\section{Arterial abnormalities in congenital heart disease}

Research in the last decade has demonstrated that patients with repaired Coarctation of the Aorta (CoA) have a higher risk of mortality than the general population or patients with other forms of coronary artery disease (CAD), ${ }^{52}$ which has been attributed predominantly to an increased prevalence of CAD in this cohort. Now, in a large sample of adult patients with CoA from Canada $(n=756)$, the diagnosis of CoA was not found to be an independent predictor for CAD development after adjustment for traditional CAD risk factors ${ }^{52}$ and this finding is supported by recent evidence of no clinically significant difference in endothelial function between adult patients with CoA and healthy controls. ${ }^{53}$

\section{Adult congenital heart disease management}

Along with the improvements in the care of CHD during the last decades, an increasing number of patients with CHD have the erroneous impression of being cured. This leads to a large number of patients lost to follow-up, which have an increased risk of developing adverse outcomes, including increased late mortality, compared with patients under specialised adult CHD (ACHD) follow-up (see figure 3). ${ }^{5455}$

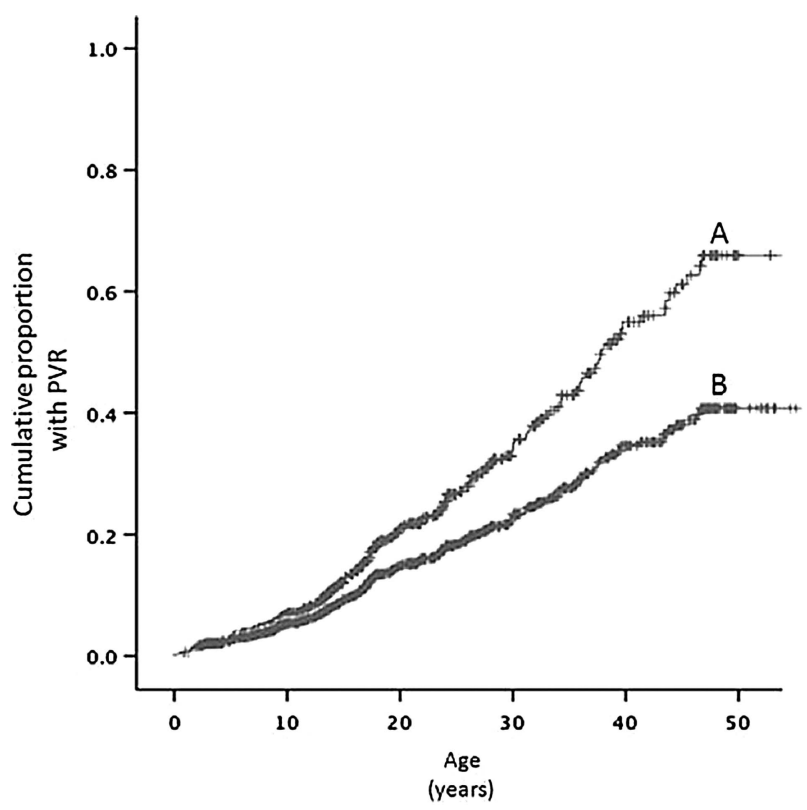

Figure 3 Prevalence of pulmonary valve replacement (PVR) stratified by quality of follow-up. Data from a UK cohort study demonstrates that the prevalence of PVRs in patients that are followed up under specialised care $(A)$ is significantly higher than in patients without such care. Adapted from Wray et al..$^{54}$
Identification of risk predictors for late adverse events in the growing population of patients with ACHD is one of the major goals in current CHD research. Recent studies show that moderate to severe impairment of lung function is an independent predictor of mortality, with an at least 1.6-fold increased risk of death compared with patients with normal lung function. ${ }^{56}$ In the same study, reduced peak oxygen uptake and heart rate reserve on cardiopulmonary exercise testing were additional predictors of mortality. ${ }^{57} \mathrm{~A}$ first set of reference values for the adult CHD population, stratified by $\mathrm{CHD}$-subtype and gender, has recently been published. ${ }^{58}$ Also, patients with ACHD who are physically more active, tend to perform better on exercise testing. ${ }^{59}$ Twenty-four weeks of structured aerobic exercise training of adult patients with TGA significantly improves cardiopulmonary exercise testing parameters and reduces HF symptoms without a negative impact on the systemic $\mathrm{RV}^{60}$ The benefits of a structured exercise programme combined with psychological training for improving overall activity in adolescents with CHD has also recently been demonstrated. ${ }^{61}$

In a study based on two large ACHD registries (including almost 40000 patients between 1996 and 2005), 30-day inhospital mortality was lower in female than in male patients. ${ }^{62}$ Male gender, along with pacemaker implantation, was also highly predictive of 3-year mortality after admission for HF in the Dutch CONgenital CORvitia (CONCOR) registry. $^{63}$ Intriguingly, women with a pregnancy history had the lowest overall mortality, which did not correlate with a higher utilisation of health services in this population. ${ }^{62}$

Survival data from a large cohort of elderly patients with ACHD ( $>60$ years of age, $n=375$ ) during 5 years of follow-up at a tertiary ACHD centre demonstrated a significantly higher mortality compared with younger patients with ACHD or the normal population. ${ }^{64}$ Strongest prognostic predictors were the presence of CAD or congestive HF, NYHA class and systemic ventricular dysfunction. Healthcare providers should anticipate a substantial increase in the number of elderly patients with ACHD over the next few decades and be prepared to meet their special problems and needs.

\section{Pregnancy and congenital heart disease}

During the last 2 years, pregnancy-related outcomes in patients with CHD have been published from large trials or registries. ${ }^{65}$ Data from the Registry On Pregnancy And Cardiac disease demonstrated that $\mathrm{HF}$ is a common complication in pregnant patients with cardiac disease (13\%, of more than 1300 participants). ${ }^{66}$ While the highest incidence of HF was found to be at the end of the second trimester or during childbirth, prevalence of HF was strongly associated with pre-eclampsia, premature birth and maternal and foetal mortality. However, patients with CHD had a relatively lower risk of developing HF compared with patients with valvular heart disease, ischaemic heart disease or cardiomyopathy. Nevertheless, the risk of cardiovascular events during pregnancy, particularly arrhythmias and death, is significantly elevated in patients with CHD (see figure 4), ${ }^{67} 68$ the rate of caesarean section is higher than background $(13 \%$ vs $8 \%)$ and offspring are more likely to have low birth weight. ${ }^{67}$ Importantly, patients with complex CHD were found to have a higher risk of adverse cardiovascular outcomes than patients with simple CHD.

ZAHARA II, a prospective multicentre cohort study of more than 200 pregnant women with CHD demonstrated suboptimal uteroplacental Doppler blood flow patterns in comparison with controls. ${ }^{69}$ On multivariate analysis, preconception tricuspid annular plane systolic excursion (a measure of RV systolic 


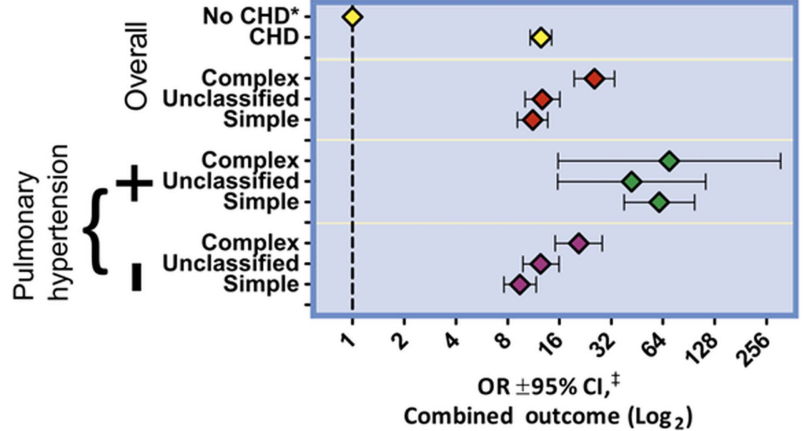

Figure 4 Adverse cardiovascular outcome during pregnancy, stratified by congenital heart disease (CHD) complexity and presence of pulmonary hypertension. Data from the largest US hospital discharge database demonstrates increased odds for adverse cardiovascular events (arrhythmias, cerebrovascular accidents, embolism, heart failure, death or a combined outcome) in patients with CHD compared with women who do not have $\mathrm{CHD}$. $\mathrm{OR} \pm 95 \% \mathrm{Cl} \mathrm{OR} \pm 95 \% \mathrm{Cl}$ on multivariate analysis; Adapted from Opotowsky et al. ${ }^{68}$

function), high precursor of B-type natriuretic peptide cTnI cardiac Troponin I (NT-pro-BNP), as well as mitral and tricuspid regurgitation were predictors of a decreased umbilical artery resistance index, which is known to be associated with adverse obstetric and offspring events. Affected women were more likely to develop pre-eclampsia and deliver small for gestational age babies (both fourfold increase). Based on these findings, preconception tricuspid annular plane systolic excursion as well as NT-pro-BNP may become helpful adjuncts in the risk assessment for women with CHD. The negative predictive value of a NT-pro-BNP $<128 \mathrm{pg} / \mathrm{mL}$ at 20 -week gestation was estimated to be $96.9 \% .^{70}$

Further details of current principles of care for pregnant patients with CHD with special sections on many CHD subtypes have recently been summarised in an excellent review article. $^{71}$

\section{Global burden of cardiovascular disease}

Large efforts have been made to improve the outcome of patients with CHD or rheumatic heart disease (RHD) in the developing world and progress can be identified in several aspects as excellently reviewed for the African continent. ${ }^{72-74}$ In their review, Zühlke et $a l^{72}$ point out that establishing comprehensive prevention programmes as well as efficient screening for subclinical RHD has highest priority, as RHD remains to be the leading cause of cardiac disease in children of low-income countries. Along these lines, a new evidence-based guideline was published by the World Heart Federation in 2012 with the intention to standardise RHD criteria on the basis of 2D and Doppler echocardiography. ${ }^{75}$ These new guidelines have been found to be highly sensitive and specific in a prospective study of a high-risk population (Australian Indigenous population). ${ }^{76}$ The increasing availability of small and portable echocardiography scanners may further help to transfer these guidelines into clinical practice even in the most resource-constrained settings, as successfully demonstrated by a group from Uganda. ${ }^{77}$ Strategies like this should help to reduce the incidence of RHD related complications, including significant mitral stenosis and tricuspid regurgitation. A group from Korea demonstrated longterm follow-up data on patients after successful percutaneous mitral valvuloplasty for rheumatic mitral stenosis (299 patients for up to 12 years) and found that the incidence for developing tricuspid regurgitation increases even years after successful percutaneous mitral commissurotomy. ${ }^{78}$ If mitral valve replacement is performed for mitral stenosis, patients also benefit from concomitant tricuspid valve replacement if they have mild-moderate tricuspid regurgitation at the time of surgery. ${ }^{79}$

On the other hand, the diagnosis of $\mathrm{CHD}$ is also often delayed in low-income countries, which is associated with significant additional burden. Thus, earlier detection of CHD on a population-wide level is the most important criterion to reduce the lifelong burden of CHD in low-income countries. In a very large prospective trial involving more than 120000 newborns in China, an example of successful implementation of pulse oximetry in low-income countries has been established, ${ }^{80}$ which helps to identify patients with major CHD that are not diagnosed on clinical investigation alone. Further advantages of this technique, as opposed to widespread implementation of echocardiography, are the low workload, the short screening time and the simplicity of its performance. In their study, the false negative rate for pulse oximetry was $0.3 \%$, while without pulse oximetry, three times more babies with critical CHDs and two times more babies with other major CHDs would have left the hospital undiagnosed.

\section{Images and case reports of congenital heart disease}

Case reports and images constitute a significant proportion of publications on congenital heart defects. For the clinician, they provide an additional educational source and are especially important to illustrate innovative techniques in interventional paediatric cardiology ${ }^{37} 81-85$ and to raise the awareness for very rare congenital pathologies. ${ }^{86-88}$ In concert with educational articles on specific topics in CHD ${ }^{89}{ }^{90}$ they provide an excellent adjunct to keep all of us in paediatric cardiology curious and up-to-date.

Contributors PCK and G-PD carried out the literature review. PCK wrote the first draft of the manuscript, which was revised and approved by both authors.

Competing interests None.

Provenance and peer review Commissioned; internally peer reviewed.

\section{REFERENCES}

1 Khoshnood B, Lelong N, Houyel L, et al. Prevalence, timing of diagnosis and mortality of newborns with congenital heart defects: a population-based study. Heart 2012;98:1667-73

2 Gardiner HM, Kovacevic A, van der Heijden LB, et al. Prenatal screening for major congenital heart disease: assessing performance by combining national cardiac audit with maternity data. Heart 2014;100:375-82.

3 Brown KL, Sullivan ID. Prenatal detection for major congenital heart disease: a key process measure for congenital heart networks. Heart 2014;100:359-60.

4 Miranda JO, Callaghan N, Miller O, et al. Right aortic arch diagnosed antenatally: associations and outcome in 98 fetuses. Heart 2014;100:54-9.

5 Marelli AJ, lonescu-Ittu R, Mackie AS, et al. Lifetime prevalence of congenital heart disease in the general population from 2000 to 2010. Circulation 2014;130:749-56.

6 van der Bom T, Bouma BJ, Meijboom FJ, et al. The prevalence of adult congenital heart disease, results from a systematic review and evidence based calculation. Am Heart J 2012;164:568-75.

7 Coats $L, O^{\prime}$ Connor $S$, Wren $C$, et al. The single-ventricle patient population: a current and future concern a population-based study in the North of England. Heart 2014; 100:1348-53.

8 Kempny A, Dimopoulos K, Gatzoulis MA. Single-ventricle physiology in the UK: an ongoing challenge of growing numbers and of growing complexity of congenital heart disease. Heart 2014;100:1315-16.

9 Schranz D. Hybrid approach in hypoplastic left heart syndrome. Heart 2014; 100:750-1

10 Frommelt PC, Guey LT, Minich LL, et al. Does initial shunt type for the Norwood procedure affect echocardiographic measures of cardiac size and function during infancy?: the Single Vventricle Reconstruction trial. Circulation 2012;125:2630-8.

11 Chetan D, Kotani $Y$, Jacques $F$, et al. Surgical palliation strategy does not affect interstage ventricular dysfunction or atrioventricular valve regurgitation in children 
with hypoplastic left heart syndrome and variants. Circulation 2013;128(11 Suppl 1):S205-12.

12 Baba K, Kotani Y, Chetan D, et al. Hybrid versus Norwood strategies for single-ventricle palliation. Circulation 2012;126(11 Suppl 1):S123-31.

13 Newburger JW, Sleeper LA, Frommelt PC, et al. Transplantation-free survival and interventions at 3 years in the single ventricle reconstruction trial. Circulation 2014;129:2013-20.

14 Lloyd DF, Cutler L, Tibby SM, et al. Analysis of preoperative condition and interstage mortality in Norwood and hybrid procedures for hypoplastic left heart syndrome using the Aristotle scoring system. Heart 2014;100:775-80.

15 Bossers SS, Cibis M, Gijsen FJ, et al. Computational fluid dynamics in Fontan patients to evaluate power loss during simulated exercise. Heart 2014; 100:696-701.

16 d'Udekem Y, Xu MY, Galati JC, et al. Predictors of survival after single-ventricle palliation: the impact of right ventricular dominance. J Am Coll Cardiol 2012;59:1178-85.

17 Rogers LS, Glatz AC, Ravishankar C, et al. 18 years of the Fontan operation at a single institution: results from 771 consecutive patients. J Am Coll Cardiol 2012;60:1018-25.

18 John AS, Johnson JA, Khan M, et al. Clinical outcomes and improved survival in patients with protein-losing enteropathy after the Fontan operation. J Am Coll Cardiol 2014:64:54-62.

19 Deal BJ, Jacobs ML. Management of the failing Fontan circulation. Heart 2012;98:1098-104.

20 Assenza GE, Graham DA, Landzberg MJ, et al. MELD-XI score and cardiac mortality or transplantation in patients after Fontan surgery. Heart 2013;99:491-6.

21 Cordina R, O'Meagher S, Gould $H$, et al. Skeletal muscle abnormalities and exercise capacity in adults with a Fontan circulation. Heart 2013;99:1530-4.

22 Shafer KM, Garcia JA, Babb TG, et al. The importance of the muscle and ventilatory blood pumps during exercise in patients without a subpulmonary ventricle (Fontan operation). J Am Coll Cardiol 2012;60:2115-21.

23 Swartz MF, Sena A, Atallah-Yunes N, et al. Decreased incidence of supravalvar pulmonary stenosis after arterial switch operation. Circulation 2012;126(11 Suppl 1):S118-22.

24 Mokhles MM, Charitos El, Stierle U, et al. The fate of pulmonary conduits after the Ross procedure: longitudinal analysis of the German-Dutch Ross registry experience. Heart 2013:99:1857-66.

25 Agus MS, Asaro LA, Steil GM, et al. Tight glycemic control after pediatric cardiac surgery in high-risk patient populations: a secondary analysis of the safe pediatric euglycemia after cardiac surgery trial. Circulation 2014;129:2297-304.

26 Cantinotti M, Assanta N, Murzi B, et al. Controversies in the definition and management of insignificant left-to-right shunts. Heart 2014;100:200-5.

27 Siddiqui J, Brizard CP, Galati JC, et al. Surgical valvotomy and repair for neonatal and infant congenital aortic stenosis achieves better results than interventional catheterization. J Am Coll Cardiol 2013;62:2134-40.

28 Yang J, Yang L, Yu S, et al. Transcatheter versus surgical closure of perimembranous ventricular septal defects in children: a randomized controlled trial. J Am Coll Cardiol 2014;63:1159-68.

29 McCrossan B, Morgan G, Grant B, et al. A randomised trial of a remote home support programme for infants with major congenital heart disease. Heart 2012;98:1523-8.

30 Pagel C, Utley M, Crowe $S$, et al. Real time monitoring of risk-adjusted paediatric cardiac surgery outcomes using variable life-adjusted display: implementation in three UK centres. Heart 2013;99:1445-50.

31 Pagel C, Crowe S, Brown K, et al. The benefits and risks of risk-adjustment in paediatric cardiac surgery. Heart 2014;100:528-9.

32 Shahian DM, Jacobs JP, Edwards FH, et al. The society of thoracic surgeons national database. Heart 2013;99:1494-501.

33 Frigiola $A$, Hughes $M$, Turner $M$, et al. Physiological and phenotypic characteristics of late survivors of tetralogy of fallot repair who are free from pulmonary valve replacement. Circulation 2013;128:1861-8.

34 Valente AM, Gauvreau K, Assenza GE, et al. Contemporary predictors of death and sustained ventricular tachycardia in patients with repaired tetralogy of Fallot enrolled in the INDICATOR cohort. Heart 2014;100:247-53.

35 Orwat S, Diller GP. Risk stratification in adults with repaired Tetralogy of Fallot: the long journey from clinical parameters and surface ECG to in-depth assessment of myocardial mechanics, volume and pressure loading. Heart 2014;100:185-7.

36 O'Meagher S, Munoz PA, Alison JA, et al. Exercise capacity and stroke volume are preserved late after tetralogy repair, despite severe right ventricular dilatation. Heart 2012;98:1595-9.

37 Lauten A, Hoyme M, Figulla HR. Severe pulmonary regurgitation after tetralogy-of-Fallot repair: transcatheter treatment with the Edwards SAPIEN XT heart valve. Heart 2012;98:623-4.

38 Ferraz Cavalcanti PE, Sá MP, Santos CA, et al. Pulmonary valve replacement after operative repair of tetralogy of Fallot: meta-analysis and meta-regression of 3118 patients from 48 studies. J Am Coll Cardiol 2013;62:2227-43.

39 Geva T. Indications for pulmonary valve replacement in repaired tetralogy of fallot: the quest continues. Circulation 2013;128:1855-7.
40 Diller GP, Kempny A, Liodakis E, et al. Left ventricular longitudinal function predicts life-threatening ventricular arrhythmia and death in adults with repaired tetralogy of fallot. Circulation 2012;125:2440-6.

41 Mongeon FP, Gurvitz MZ, Broberg CS, et al. Aortic root dilatation in adults with surgically repaired tetralogy of fallot: a multicenter cross-sectional study. Circulation 2013;127:172-9.

42 Khairy P, Clair M, Fernandes SM, et al. Cardiovascular outcomes after the arterial switch operation for D-transposition of the great arteries. Circulation 2013;127:331-9

43 van der Bom T, Winter MM, Bouma BJ, et al. Effect of valsartan on systemic right ventricular function: a double-blind, randomized, placebo-controlled pilot trial. Circulation 2013:127:322-30.

44 van der Bom T, Winter MM, Groenink M, et al. Right ventricular end-diastolic volume combined with peak systolic blood pressure during exercise identifies patients at risk for complications in adults with a systemic right ventricle. J Am Coll Cardiol 2013;62:926-36

45 Cuypers JA, Eindhoven JA, Slager MA, et al. The natural and unnatural history of the Mustard procedure: long-term outcome up to 40 years. Eur Heart J 2014;35:1666-74.

46 Moceri P, Dimopoulos K, Liodakis E, et al. Echocardiographic predictors of outcome in eisenmenger syndrome. Circulation 2012;126:1461-8.

47 Diller GP, Alonso-Gonzalez R, Kempny A, et al. B-type natriuretic peptide concentrations in contemporary Eisenmenger syndrome patients: predictive value and response to disease targeting therapy. Heart 2012;98:736-42.

48 Kempny A, Dimopoulos K, Alonso-Gonzalez R, et al. Six-minute walk test distance and resting oxygen saturations but not functional class predict outcome in adult patients with Eisenmenger syndrome. Int I Cardiol 2013;168:4784-9.

49 Douwes JM, Roofthooft MTR, Van Loon RLE, et al. Sildenafil add-on therapy in paediatric pulmonary arterial hypertension, experiences of a national referral centre. Heart 2014;100:224-30.

50 Barst RJ, McGoon MD, Elliott CG, et al. Survival in childhood pulmonary arterial hypertension: insights from the registry to evaluate early and long-term pulmonary arterial hypertension disease management. Circulation 2012;125:113-22.

51 Zijlstra WM, Douwes JM, Rosenzweig EB, et al. Survival differences in pediatric pulmonary arterial hypertension: clues to a better understanding of outcome and optimal treatment strategies. J Am Coll Cardiol 2014;63:2159-69.

52 Roifman I, Therrien J, Ionescu-Ittu R, et al. Coarctation of the aorta and coronary artery disease: fact or fiction?. Circulation 2012;126:16-21.

53 Radke RM, Diller G-P, Duck M, et al. Endothelial function in contemporary patients with repaired coarctation of aorta. Heart 2014;100:1696-701.

54 Wray J, Frigiola A, Bull C. Loss to specialist follow-up in congenital heart disease; out of sight, out of mind. Heart 2013;99:485-90.

55 Wren C, O'Sullivan J. Loss to follow-up of adults with repaired congenital heart disease. Heart 2013;99:440-1.

56 Alonso-Gonzalez R, Borgia F, Diller G-P, et al. Abnormal lung function in adults with congenital heart disease: prevalence, relation to cardiac anatomy, and association with survival. Circulation 2013;127:882-90.

57 Inuzuka R, Diller G-P, Borgia F, et al. Comprehensive use of cardiopulmonary exercise testing identifies adults with congenital heart disease at increased mortality risk in the medium term. Circulation 2012;125:250-9.

58 Kempny A, Dimopoulos K, Uebing A, et al. Reference values for exercise limitations among adults with congenital heart disease. Relation to activities of daily lifesingle centre experience and review of published data. Eur Heart $J$ 2012:33:1386-96.

59 Ubeda Tikkanen A, Opotowsky AR, Bhatt AB, et al. Physical activity is associated with improved aerobic exercise capacity over time in adults with congenital heart disease. Int J Cardiol 2013;168:4685-91.

60 Westhoff-Bleck M, Schieffer B, Tegtbur U, et al. Aerobic training in adults after atrial switch procedure for transposition of the great arteries improves exercise capacity without impairing systemic right ventricular function. Int I Cardiol 2013:170:24-9.

61 Morrison ML, Sands AJ, McCusker CG, et al. Exercise training improves activity in adolescents with congenital heart disease. Heart 2013;99:1122-8.

62 Zomer AC, Ionescu-lttu R, Vaartjes I, et al. Sex differences in hospital mortality in adults with congenital heart disease: the impact of reproductive health. J Am Coll Cardiol 2013;62:58-67.

63 Zomer AC, Vaarties I, van der Velde ET, et al. Heart failure admissions in adults with congenital heart disease; risk factors and prognosis. Int I Cardiol 2013;168:2487-93.

64 Tutarel $\mathrm{O}$, Kempny A, Alonso-Gonzalez R, et al. Congenital heart disease beyond the age of 60: emergence of a new population with high resource utilization, high morbidity, and high mortality. Eur Heart I 2014;35:725-32.

65 Krieger EV, Stout K. Progress: the ROPAC multinational registry advances our understanding of an important outcome in pregnant women with heart disease. Heart 2014;100:188-9.

66 Ruys TP, Roos-Hesselink JW, Hall R, et al. Heart failure in pregnant women with cardiac disease: data from the ROPAC. Heart 2014;100:231-8. 
67 Roos-Hesselink JW, Ruys TPE, Stein Jl, et al. Outcome of pregnancy in patients with structural or ischaemic heart disease: results of a registry of the European Society of Cardiology. Eur Heart J 2013;34:657-65.

68 Opotowsky AR, Siddiqi OK, D'Souza B, et al. Maternal cardiovascular events during childbirth among women with congenital heart disease. Heart 2012;98:145-51.

69 Pieper PG, Balci A, Aarnoudse JG, et al. Uteroplacental blood flow, cardiac function, and pregnancy outcome in women with congenital heart disease. Circulation 2013;128:2478-87.

70 Kampman MA, Balci A, van Veldhuisen DJ, et al. N-terminal pro-B-type natriuretic peptide predicts cardiovascular complications in pregnant women with congenital heart disease. Eur Heart J 2014;35:708-15.

71 Brickner ME. Cardiovascular management in pregnancy: congenital heart disease. Circulation 2014;130:273-82.

72 Zuhlke L, Mirabel M, Marijon E. Congenital heart disease and rheumatic heart disease in Africa: recent advances and current priorities. Heart 2013;99:1554-61.

73 Mocumbi AO, Sliwa K. Women's cardiovascular health in Africa. Heart 2012;98:450-5.

74 Mocumbi AO, Falase AO. Recent advances in the epidemiology, diagnosis and treatment of endomyocardial fibrosis in Africa. Heart 2013;99:1481-7.

75 Remenyi B, Wilson N, Steer A, et al. World Heart Federation criteria for echocardiographic diagnosis of rheumatic heart disease - an evidence-based guideline. Nat Rev Cardiol 2012;9:297-309.

76 Roberts K, Maguire G, Brown A, et al. Echocardiographic screening for rheumatic heart disease in high and low risk Australian children. Circulation 2014;129:1953-61.

77 Beaton A, Okello E, Lwabi P, et al. Echocardiography screening for rheumatic heart disease in Ugandan schoolchildren. Circulation 2012;125:3127-32.

78 Lee SP, Kim H-K, Kim K-H, et al. Prevalence of significant tricuspid regurgitation in patients with successful percutaneous mitral valvuloplasty for mitral stenosis: results from 12 years' follow-up of one centre prospective registry. Heart 2013;99:91-7.
79 Kim JB, Yoo DG, Kim GS, et al. Mild-to-moderate functional tricuspid regurgitation in patients undergoing valve replacement for rheumatic mitral disease: the influence of tricuspid valve repair on clinical and echocardiographic outcomes. Heart 2012;98:24-30.

80 Zhao Q-M, Ma XJ, Ge XL, et al. Pulse oximetry with clinical assessment to screen for congenital heart disease in neonates in China: a prospective study. Lancet 2014;384:747-54.

81 Agnoletti G, Bordese R, Gabbarini F. Closure of a large ductus arteriosus in a preterm infant using the ADO II AS device. Heart 2012;98:1394.

82 Cunnington C, Hampshaw SA, Mahadevan VS. Utility of real-time three-dimensional intracardiac echocardiography for patent foramen ovale closure. Heart 2013;99:1789-90.

83 Duerr GD, Breuer J, Schiller W. A new transventricular aproach for pulmonary valve implantation in a patient with severe valve disease after tetralogy-of-Fallot repair. Heart 2013;99:1469-70.

84 Edwards NC, Griffiths M, Steeds RP. Intra-cardiac echocardiography in mitral valve repair: a novel use of a complimentary imaging modality in a difficult scenario. Heart 2013;99:1791-2.

85 Gopalamurugan AB, Reinthaler M, Mullen MJ. Percutaneous valve-in-valve implantations: importance of knowing the effective internal diameter of bioprosthetic valves. Heart 2013;99:1709-10.

86 Rider OJ, Bissell M, Myerson SG. Congenital aortopulmonary window; an unusual cause of breathlessness. Heart 2013;99:1546.

87 Lutaaya M, Rajagopal R, More RS. Giant unruptured Sinus of Valsalva aneurysm: an unusual cause of aortic regurgitation. Heart 2013;99:972.

88 Frontera A, Thomas G, Duncan E. Cardiac arrest in concomitant Wolff-Parkinson-White syndrome and early repolarisation: is pathway ablation enough? Heart 2014;100:598-9.

89 Vettukattil JJ. Three dimensional echocardiography in congenital heart disease. Heart 2012;98:79-88.

90 Cuypers JA, Witsenburg M, van der Linde $D$, et al. Pulmonary stenosis: update on diagnosis and therapeutic options. Heart 2013;99:339-47. 